\title{
Kianoosh Rezania. "On the Old Iranian Social Space and its Relation to the Time ordering System"
}

Samra Azarnouche

\section{(2) OpenEdition}

1 Journals

\section{Édition électronique}

URL : http://journals.openedition.org/abstractairanica/43550

DOI : 10.4000/abstractairanica.43550

ISBN : 1961-960X

ISSN : 1961-960X

Éditeur :

CNRS (UMR 7528 Mondes iraniens et indiens), Éditions de l'IFRI

Référence électronique

Samra Azarnouche, « Kianoosh Rezania. "On the Old Iranian Social Space and its Relation to the Time ordering System" ", Abstracta Iranica [En ligne], Volume 37-38-39 | 2018, document 4, mis en ligne le 30 décembre 2018, consulté le 10 décembre 2020. URL : http://journals.openedition.org/ abstractairanica/43550 ; DOI : https://doi.org/10.4000/abstractairanica.43550

Ce document a été généré automatiquement le 10 décembre 2020.

Tous droits réservés 


\title{
Kianoosh Rezania. "On the Old Iranian Social Space and its Relation to the Time ordering System"
}

\author{
Samra Azarnouche
}

\section{RÉFÉRENCE}

Kianoosh Rezania. "On the Old Iranian Social Space and its Relation to the Time ordering System" in A. Krasnowolska, R. Rusek-Kowalska (eds.). Studies on the Iranian World I: Before Islam. Proceedings of the 7th European Conference of Iranian Studies (Crakow 2011). Krakow: Jagellonian University Press, 2015, p. 177-190.

1 L'Avesta récent présente une structure socio-spatiale (famille, clan, tribu, nation, zaraӨštrō.təma; Y 19.18) qui est mise en parallèle avec un système socio-rituel correspondant à l'ordre temporel des cinq moments de la journée (Y 17.2-6). Ainsi le premier moment, Ušahina, serait associé à la plus petite unité sociale, la famille. C'est ce qu'on observe dans les mss sāde du Yasna et du Wisprad, tandis que ceux du Wīdēwdād placent en tête de liste le deuxième moment, Hāuuani. Pour expliquer ce décalage, l'A. émet l'hypothèse que la correspondance entre les moments de la journée et les moments rituels (les ratu- ou " articulations ») était modifiée en fonction du type de cérémonie et la fréquence de sa célébration. Ainsi le Yasna journalier correspond au premier moment et à l'unité de la maison ; le Wisprad ì Gāhānbār saisonnier se tient au deuxième temps et dans le clan, et le Rapiøßina annuel se tient au troisième temps et dans la tribu. Ces correspondances rituelles entre espace et temps auraient été mises en place à l'époque de la rédaction de l'Avesta récent. 


\section{AUTEURS}

\section{SAMRA AZARNOUCHE}

EPHE, Mondes iranien et indien, Paris 